\title{
MOBILIDADES E ESCRITOS: MENSAGENS TROCADAS (SÃO PAULO - PORTUGAL 1890-1950)
}

\author{
Writings and displacements: messages exchanged \\ (São Paulo-Portugal 1890-1950) \\ Maria Izilda Santos de Matos*
}

\begin{abstract}
RESUMO
Os deslocamentos dos portugueses incluíram uma diversidade de trajetórias e multiplicidade de experiências, processos diferentes e simultâneos que compuseram uma trama histórica. Incorporando a perspectiva cultural, esta investigação centra-se na análise das cartas, correspondências e mensagens localizadas no Memorial do Imigrante de São Paulo (antiga Hospedaria dos Imigrantes) e em arquivos portugueses (Arquivo Distrital do Porto e Arquivo Distrital de Braga).
\end{abstract}

Palavras-chave: deslocamentos; portugueses; cartas.

\begin{abstract}
The displacements of the Portuguese included a variety of trajectories and experiences, different processes composing the web historical. Incorporating cultural perspective, this research focuses on the analysis of letters, correspondence and messages found in the Immigrant Memorial of São Paulo (old Hospedaria dos Imigrantes) and Portuguese archives (Archive District of Porto and Archive District of Braga).
\end{abstract}

Keywords: displacement; Portugueses; letters.

\section{Mobilidades}

As facilidades e agilidades das viagens, somadas às múltiplas possibilidades de comunicação, dinamizam os deslocamentos, tornando-os

* PUC/SP e CNPq. 
um "fenômeno" perceptível e provocando tensões, hostilidades, rejeições, conflitos e xenofobia nas sociedades receptoras. Estas tensões atuais levam ao reconhecimento da importância da temática das mobilidades e ampliam-se os estudos com diferenciadas perspectivas de análise, iluminando interpretações, enriquecendo abordagens e contribuindo para rever estereótipos.

Cabe ressaltar a necessidade de que os deslocamentos sejam analisados além dos condicionamentos demográfico-econômico-sociais e do paradigma mecanicista da miserabilidade; assim, não podem ser vistos apenas como resposta às condições excepcionais de pobreza ${ }^{1}$, fruto das pressões do crescimento da população (modelo malthusiano) ou de mecanismos impessoais do push-pull dos mercados internacionais. Estes processos superaram os limites das necessidades estritamente econômicas, sendo importante observar questões políticas (refugiados, perseguidos e expulsos), étnico-raciais, culturais, religiosas, geracionais e de gênero. ${ }^{2}$

Os deslocamentos aparecem como alternativas adotadas por uma gama abrangente de sujeitos históricos, alguns inseridos em fluxo de massa, grupos familiares ou em percursos individuais; através de processos de migração engajada ou voluntária, abarcando diversos estratos sociais, levas e gerações; envolvendo agentes inspirados por estratégias e motivações diferenciadas, inclusive culturais e existenciais. Entre as múltiplas motivações que levaram às mobilidades, encontram-se a procura da realização de sonhos, a abertura de novas perspectivas, as fugas das pressões cotidianas e a busca do "fazer a América", em variadas representações construídas e vitalizadas neste universo.

Cabe ressaltar os mecanismos que viabilizaram este processo, particularmente, a constituição de redes $^{3}$, com o estabelecimento de relações interpessoais e institucionais (agenciadores, aliciadores, aparatos de

1 Não basta que existam dificuldades econômicas para que os deslocamentos ocorram, estas dificuldades têm que estar vinculadas à percepção de que a emigração é uma alternativa aceitável e os canais necessários têm que estar constituídos para viabilizar as saídas. BAGANHA, Maria Ioannis. Migração transatlântica: uma síntese histórica. In: PEREIRA, M. H.; SERRÃO. J. V.; PINHEIRO, M; FERREIRA, M. F. S. M. Desenvolvimento econômico e mudança social: Portugal nos últimos dois séculos: homenagem a Miriam Halpern Pereira. Lisboa: Imprensa de Ciências Sociais, 2009.

2 CORTI, Paola. Storia delle migrazioni internazionali. Roma: Editori Laterza, 2007.

3 A categoria rede de e-imigração incorpora tanto as ações familiares e comunitárias como as estruturas impessoais de informação, difusão e apoio, articulando-se a noção de cadeia proposta por MACDONALD, J.; MACDONALD Leatrice. Chain Migration Ethnic Neighborhood Formation and Social Networks. The Milbank Memorial Fund Quarterly, v. XLII, n. 1, p; 82-97, 1964. 
propaganda, meios de comunicação), além da organização do sistema de navegação comercial, que viabilizou o transporte transoceânico em massa. Assim, se pretende discutir vínculos estabelecidos, circuitos de sustentação nas regiões de saída e de acolhimento, expectativas e sonhos construídos no processo, tensões e frustrações, possibilidades de reencontros e reconstituição familiar.

\section{Sonho americano: historiografia}

No Brasil, a temática da imigração vem sendo privilegiada pela historiografia, tendo produção ampla, diversificada e enriquecida por abordagens que analisam aspectos diferenciados da questão. Os deslocamentos ibéricos só mais recentemente têm instigado os pesquisadores ${ }^{4}$; contudo, parte significativa dos trabalhos se volta para o Rio de Janeiro, onde a presença portuguesa foi significativa e marcante. ${ }^{5}$

Os estudos sobre imigração em São Paulo privilegiaram certos grupos, em particular, os italianos e japoneses. Só contemporaneamente

4 Para a produção em Portugal destacaríamos o livro de PEREIRA, Miriam Halpern. $A$ política portuguesa de Emigração, 1850-1930. Bauru: EDUSC, 2002; CRUZ, Maria Antonieta. Agruras dos emigrantes portugueses no Brasil. Porto, 1987; RODRIGUES, Henrique. Alto Minho no século XIX: contextos migratórios, socioculturais e familiares. Tese (Doutoramento) - FLUP. Porto, 2003. ALVES, Jorge Fernandes. Os brasileiros. s/e., Porto, 1994.

5 RIBEIRO, Gladys S. Mata Galegos - Os portugueses e os conflitos de trabalho na República Velha. São Paulo: Brasiliense, 1990; RIBEIRO, Gladys S. “Cabras” e "Pés de chumbo": os rolos do tempo. O antilusitanismo na cidade do RJ, 1889-1930. Dissertação (Mestrado) - UFF. Rio de Janeiro, 1987; LIMA, M. Helena Beozzo. A missão herdada. Um estudo sobre a inserção de imigrante. Tese (Mestrado) - UFPR. Rio de Janeiro: Museu Nacional, 1973; ALENCASTRO, Luis Filipe. Proletários e escravos - Imigrantes portugueses e cativos africanos no RJ (1850-1872). In: Novos Estudos Cebrap, n. 21, p. 30, jul. 1988; SILVA, M. Manuela R. S. Ambição e horror à farda ou a Saga dos imigrantes portugueses no Brasil segundo a Gazeta Luzitana (1883-1889). Tese (Doutorado) - FFLCH-USP. São Paulo, 1991; HAHNER, June E. Jacobinos versus Galegos. Urban Radicals Versus Portugueses Immigrants in RJ, in 1890s. Journal of Interamericam Studies and World Affairs, v. 18, n. 2, 1976; SOUSA, Fernando; MARTINS, Ismênia; MATOS, M. Izilda S. Nas duas margens: os portugueses no Brasil. Porto: CEPESE, 2009; MARTINS, Ismênia; SOUSA, Fernando. Portugueses no Brasil: migrantes em dois atos. Rio de Janeiro/ Porto: Muiraquitã/CEPESE, 2006; MARTINS, Ismênia; SOUSA, Fernando. A emigração portuguesa para o Brasil. Rio de Janeiro/Porto: CEPESE, 2007; MATOS, M. Izilda S.; SOUSA, Fernando. Deslocamentos \& histórias: os portugueses. Bauru/Porto: EDUSC/CEPESE, 2008. 
apareceram trabalhos que analisam os ibéricos e, entre eles, os portugueses ${ }^{6}$, sendo algumas destas investigações sob a perspectiva cultural.

A chegada dos trilhos da ferrovia Santos-Jundiaí (1863) conectou a cidade de São Paulo com o porto exportador - Santos - e a com a zona produtora de café (no interior do Estado). Os trilhos não só transportavam rápida e eficientemente o café, mas também traziam de várias partes do mundo, particularmente da Europa, uma ampla gama de imigrantes, além de toda uma variedade de produtos e influências, gerando e dinamizando um "vetor modernizador".

Neste período, a expansão urbana de São Paulo esteve vinculada diretamente aos sucessos e/ou dificuldades da economia cafeeira. A cidade consolidou-se como centro econômico e político, polo de desenvolvimento industrial, mercado distribuidor e receptor de produtos e serviços. No ano de 1872, a população de São Paulo era de 31.385 pessoas; segundo o censo de 1890, elevou-se para 64.934 habitantes; já em 1900, eram 239.820 moradores. Em 1920, a população da cidade mais do que dobrou, atingindo a cifra de 579.033 pessoas. $^{7}$

O "sonho americano" e a atração exercida pela cidade prosseguiam, concentrando um significativo contingente de trabalhadores. Enquanto uns dirigiam-se para o comércio, outros ficavam nas atividades por conta própria ou foram impelidos para o trabalho assalariado em vários ramos: indústria, comércio, obras públicas e serviços.

Entre 1920 e 1940, a população da cidade mais que duplicou, saltando para 1.326.261 habitantes. ${ }^{8}$ Em 1934, totalizavam 287.690 estrangeiros (destes, 79.465 eram portugueses) ${ }^{9}$, que formavam um mosaico diversificado de grupos étnicos com seus descendentes, que, juntamente com os migrantes, constituíam uma multiplicidade de culturas, tradições e sotaques.

6 FRUTUOSO, M. Suzel G. A emigração portuguesa e sua influência no Brasil: o caso de Santos (1850-1950). Dissertação (Mestrado) - FFLCH/USP. São Paulo, 1989; FREITAS, Sonia M. Presença portuguesa em São Paulo. São Paulo: Imprensa Oficial, 2006; MATOS, M. Izilda Santos de; SOUSA, Fernando. Deslocamentos \& histórias: os portugueses. Bauru/Porto: EDUSC/CEPESE, 2008; PASCAL, M. Aparecida. Portugueses em São Paulo. São Paulo: Expressão e Arte, 2005.

7 Ministério da Agricultura, Indústria e Comércio. Recenseamento do Brasil, 1920, Synopse do Recenseamento. Rio de Janeiro, Typ. da Estatística, 1926.

8 Idem, ibidem.

9 Censo Estadual de 1934. ARAÚJO, Oscar Egídio de. Enquistamentos étnicos. Revista do Arquivo Municipal, v. LXV, mar. 1940. 


\section{Mobilidades: políticas e ações}

A imigração portuguesa para o Brasil foi um processo contínuo, que envolveu experiências múltiplas e diversificadas, abarcando várias levas de diferentes regiões do continente e das ilhas; alguns vieram subsidiados, outros por conta própria; alguns chegaram no começo do processo (nos anos finais do século XIX e nos iniciais do XX), outros após a Primeira Grande Guerra ou durante o período salazarista.

Entre 1887 e 1900, os portugueses representaram 10\% do total de entradas em São Paulo, proporção que, entre 1900 e 1920, subiu para mais de $29 \%$. Em termos de período, os anos de 1910 a 1914 marcaram a vinda do maior contingente luso (111.491), em função da crise econômico-social e das dificuldades políticas com o fim do regime monárquico português e também pela preferência dos imigrantistas paulistas por esse grupo. ${ }^{10}$

Os portugueses emigravam por vários motivos: dificuldades econômicas, sociais e familiares, fugas ao recrutamento militar, poucas oportunidades de trabalho, baixos salários, tipo de propriedade e sua exploração, tensões políticas, atraso tecnológico, além do desejo de "fazer a América". Assim, as partidas foram contínuas e frequentes, vinculadas aos descontentamentos, estratégias de sobrevivência, buscas de outras possibilidades e realizações de sonhos.

Para o recrutamento de imigrantes portugueses, foi organizada toda uma rede regular de propaganda, divulgação de informações (notícias na imprensa, panfletos, cartas), agenciamento e transporte, com a participação de companhias e engajadores. Alguns recebiam subsídios do governo brasileiro e/ou paulista ou trabalhavam para eles. Constituiu-se uma cadeia que tinha como elos moradores das aldeias e freguesias, religiosos, autoridades e empresários. Esta rede funcionou entre Portugal continental, as Ilhas e o Brasil e passou a ser intensificada tendo como destino o porto de Santos, nos anos iniciais do século XX. ${ }^{11}$

10 Depois do Decreto Prinetti (1902, pelo qual o governo italiano proibiu a emigração subsidiada para São Paulo) e de medida similar do governo espanhol, reduziram-se consideravelmente as entradas de italianos e espanhóis, passando-se a priorizar os lusos. Boletins do Serviço de Imigração e Colonização, n. 2, outubro de 1940. Secretaria da Agricultura, Indústria e Comércio do Estado de São Paulo.

11 PEREIRA, Miriam Halpern. A política portuguesa de emigração. Op. cit. 
Quanto à política portuguesa de emigração, em seu processo pode ser considerada ambígua: ora repressiva (especificamente em relação aos jovens, mulheres sós e saídas clandestinas), ora permissiva. A emigração sofria a oposição dos grandes proprietários rurais, para os quais significava a evasão de braços. Estes pressionavam o governo para conter as saídas, mas o governo via na emigração uma possibilidade de limitar as tensões no campo, além de sustentar as remessas, que adquiriram importância nas finanças portuguesas, estimulando investimentos e sendo decisivas na balança de pagamentos.

Os deslocamentos eram uma possibilidade frente aos problemas sociais no campo e nas cidades portuguesas. Os emigrantes eram majoritariamente do Norte de Portugal, área de predominância da pequena proprieda$\mathrm{de}^{12}$; os que vinham do Noroeste eram em sua maior parte homens sozinhos (solteiros e casados); já entre os do Nordeste predominava a emigração familiar. No Sul, o interesse nas saídas tornou-se mais expressivo a partir das crises advindas com a Primeira Grande Guerra. ${ }^{13}$

Uma análise sobre os emigrados permite observar tendências: numa primeira, nota-se os que vinham por conta própria, destacando-se os jovens solteiros, alfabetizados, com algum capital, em busca de constituir uma trajetória profissional; geralmente possuíam contatos já estabelecidos no Brasil. Um segundo grupo era formado por homens adultos, muitas vezes casados, artesãos de profissão, que se fixavam nas grandes cidades (preferencialmente São Paulo e Rio de Janeiro), sendo que muitos destes buscavam retornar a Portugal depois de juntar algum pecúlio. ${ }^{14}$ Outro grupo era dos que vinham subsidiados, embarcavam em família, motivados pelas dificuldades econômicas, sem entrever possibilidades efetivas de regresso. ${ }^{15}$

A emigração masculina continuamente ultrapassou a familiar. As saídas de família eram o centro das preocupações das autoridades portuguesas, pois, além de provocar a desaceleração do crescimento demográfico

12 PASCHKES, Maria Luisa N. de Almeida. Notas sobre os imigrantes portugueses no Brasil (sécs. XIX e XX). Revista Histórica, USP, São Paulo, n. 123-124, p. 88-89, ago/jul. 1990/1991.

13 LEITE, Joaquim da Costa. O Brasil e a emigração portuguesa (1855-1914). In: FAUSTO, Boris (Org.). Fazer a América. São Paulo: Edusp, 2000, p. 192.

14 Estes retornados recebiam a alcunha de "brasileiros de torna-viagem" e procuravam se inserir na comunidade, investindo e realizando benesses nas suas regiões. Geravam reações ambíguas, aceitos por uns e menosprezados por outros.

15 LEITE, Joaquim da Costa. Op. cit., p. 193-194. 
(com o envelhecimento da população e a falta de perspectivas matrimoniais), afetavam as remessas de recursos para Portugal.

São as remessas dos emigrantes que permitem equilibrar uma balança de pagamentos de outro modo deficitária e encobrem uma subordinação externa, que contribuem assim para acentuar [...]. É nesse novo contexto socioeconômico que se insere a emigração portuguesa para o Brasil, destino preferido pela esmagadora maioria dos portugueses até muito recentemente. ${ }^{16}$

A prática dos homens saírem primeiro visava criar condições para chamar os familiares, podendo ser identificada como uma ação preventiva frente aos possíveis infortúnios. Contudo, estas saídas afetaram a estrutura familiar, ampliando a responsabilidade das mulheres, que passaram a arcar com os cuidados e o sustento dos filhos, a manutenção da propriedade e negócios, além das atividades domésticas.

Se a emigração portuguesa foi a princípio prioritariamente masculina, o contingente feminino cresceu gradualmente, podendo-se verificar um aumento no número de mulheres casadas, ampliando a emigração familiar de acordo com os parâmetros da política imigrantista paulista. Na primeira década do século XX, a porcentagem de mulheres alcançava mais de $25 \%$ do total de entradas e, no início da segunda, oscilou entre $35 \%$ e $40 \%$. Assim, a imigração lusa, até então caracterizada como individual, masculina e temporária, tornou-se, tendencialmente, familiar e permanente.

Durante o Governo Vargas (1930-45), foram criadas medidas restritivas às entradas e ampliaram-se as preocupações em filtrar os imigrantes que melhor se adaptassem ao país. Apesar da política anti-imigratória, os deslocamentos portugueses foram defendidos por autoridades brasileiras e portuguesas ${ }^{17}$ - que apregoavam a exclusão do sistema de cotas, con-

16 PEREIRA, Miriam Halpern. Op. cit, , p. 11-12.

17 Várias manifestações de políticos, empresários e a própria Federação das Indústrias do Estado de São Paulo pediram a equiparação dos portugueses aos brasileiros natos. Arrolavam-se os méritos dos portugueses: capacidade de assimilação, adaptabilidade e "seu incontestável valor eugênico". Sugeria-se a preferência por operários especializados, com formação técnica, além de artífices, frente à carência desta mão de obra. SIMÕES, Nuno. Portugueses no mundo. Portugal: Minerva, 1940. 
cretizando-se nas leis que favoreceram os lusos em detrimento de outros estrangeiros. ${ }^{18}$

Cabe destacar que não houve um único padrão de mobilidade: muitos imigrantes eram chefes de família e vieram antes de seus familiares, que ficaram aguardando as chamadas; outros chegaram crianças ou jovens, sem a família nuclear; em outros casos, a família veio junto, mas algumas delas não permaneceram unidas no novo contexto ou nunca se encontraram e/ou não voltaram a se constituir, gerando toda uma complexidade de situações vivenciadas.

\section{Escritos: laços de união}

Falar da imigração portuguesa constitui "o resultado histórico de um encontro entre o sonho individual e uma atitude coletiva" "19; assim, se sintetiza a importância das histórias de vida para entender o conjunto de experiências individuais e transformações sociais. Esta investigação se insere numa corrente que pretende estabelecer as articulações entre relações sociais, étnicas, de gêneros, gerações, práticas e modos de vida, numa perspectiva de incorporar os imigrantes portugueses (homens, mulheres e crianças) à história, cessando de considerá-los como objeto dado para conhecê-los como sujeitos históricos, que se constroem na e pela experiência cotidiana, procurando integrar as tensões sociais de um processo permeado por resistências, conflitos e confrontos.

18 Foram várias restrições na política imigratória a partir de 1930, presentes na "Lei dos 2/3" (decreto 19.482, de 12/12/1930), que garantia a cota de $2 / 3$ de trabalhadores brasileiros natos em todas as categorias profissionais. O Decreto $\mathrm{n}^{\circ} 406$, art. $2^{\circ}$, "o governo reserva-se o direito de limitar ou suspender por motivos econômicos ou sociais a entrada de indivíduos de determinadas raças ou origens". Já o Decreto $\mathrm{n}^{\circ} 3.010$, de 20 de agosto de 1938, art. $1^{\circ}$, que regulamenta o anterior, "ter-se-á em vista preservar a constituição étnica do Brasil, suas formas políticas e seus interesses econômicos e culturais", o que favorecia a imigração lusa. Na mesma época, a Resolução 34 do Conselho de Imigração e Colonização $(22 / 4 / 1939)$ revogou qualquer restrição numérica às entradas de portugueses. Além disso, buscando atrair os lusos, o governo assumiu as despesas de desembarque e hospedagem pelos seis dias iniciais. MENDES, José Sacchetta Ramos. Laços de sangue: privilégio e intolerância à imigração portuguesa no Brasil. Porto: CEPESE, 2010.

19 PEREIRA, Miriam Halpern. Op. cit., p. 9. 
Reconhece-se a pesquisa empírica como elemento indispensável e, neste sentido, valoriza-se o uso de uma diversidade de fontes, que constituem um mosaico de referências do passado, com destaque para as cartas. A dificuldade enfrentada pelo investigador está mais na fragmentação do que na ausência documental, requerendo uma paciente busca de indícios, sinais e sintomas, acrescida da análise detalhada para esmiuçar o implícito e oculto, atentando para os múltiplos significados da documentação.

Os estudos das cartas e correspondências tem privilegiado as escrituras de figuras de destaque intelectual e político. Na atual pesquisa, as missivas endereçadas e recebidas envolveram sujeitos históricos populares e anônimos - e/imigrantes lusos -, tornando a análise mais complexa, porém com grande potencial para descobertas, cabendo observar que

[...] A correspondência é um tipo de documentação abundante e variadíssima, mas também fragmentada, dada a dispersão e, muitas vezes, quase inacessível, pelas barreiras impostas pelos segredos (familiares, políticos, profissionais) e pela invasão de privacidade que seu exame pode acarretar. Além disso, o pesquisador precisa estar ciente de uma série de procedimentos metodológicos para que sua análise tenha maior rendimento. Trabalhar com cartas, assim como com outros documentos, privados ou não, implica procurar atentar para uma série de questões e respondê-las. Quem escreve/lê as cartas? Em que condições e locais foram escritas? Onde foram encontradas e como estão guardadas? Qual ou quais os seus objetivo (s)? Qual o seu ritmo e volume? Quais as suas características como objeto material? Que assuntos/temas envolvem? Como são explorados em termos de vocabulário e linguagem? Estas questões podem se multiplicar, chamando a atenção do analista para as importantes relações estabelecidas entre quem escreve o que escreve e o suporte material usado na escrita. ${ }^{20}$

As cartas dos e/imigrantes se caracterizam como um testemunho precioso de fragmentos de diálogos entre dois mundos, mas ainda são fontes pouco exploradas nos estudos dos deslocamentos. Deve-se advertir que as

p. 21.

20 GOMES, Angela de Castro. Escrita de si, escrita da história. Rio de Janeiro: FGV, 2004, 
missivas se constituem num corpo documental irregular: apesar de serem dirigidas a um destinatário (com o qual se deseja estabelecer uma prática interativa), muitas vezes não se obtinham respostas, foram extraviadas ou então não foram preservadas.

Os escritos epistolares encontram-se marcados pelos desejos da manutenção dos vínculos com as origens, possibilitando perceber trocas de notícias, relações de família e de gênero, analisar o cotidiano e a vida privada, além de captar as sensibilidades.

Nesta investigação, as cartas se destacam não só pela sua quantidade, mas pela riqueza de seus relatos, permitindo maior compreensão do processo de deslocamento dos portugueses para São Paulo-Brasil. As correspondências foram localizadas na Hospedaria do Imigrante de São Paulo ${ }^{21}$ e em arquivos portugueses (Arquivo Distrital do Porto e Arquivo Distrital de Braga).

Nestes acervos foram encontradas missivas variadas: cartas oficiais e de chamada, correspondência familiar e de negócios, algumas prestando contas, outras só informativas. Elas privilegiavam questões da vida doméstica e do cotidiano, relatavam tensões familiares e dificuldades, faziam referências às remessas e seus aplicativos; já outros escritos eram pessoais e até íntimos, expondo relações afetivas de amor, rancor, ruptura e saudades, desabafos e confidências.

\section{Mobilidades e escrituras: presenças na ausência}

Apesar da sua ancestralidade, a escrita epistolar se alargou com a ampliação das comunicações e a intensificação das mobilidades. Facilitados

21 Fundada em 1886/87, a Hospedaria visava abrigar os recém chegados na cidade de São Paulo, sendo permitido permanecer no local por até oito dias. Havia um setor no qual os imigrantes se encontravam com os empregadores, para firmar os contratos de trabalho. MOURA, Soraya; PAIVA, Odair da Cruz. Hospedaria de Imigrantes de São Paulo. São Paulo: Paz e Terra, 2008. Na sua trajetória histórica, a Hospedaria esteve vinculada e/ou subordinada a várias Inspetorias, Secretarias e Departamentos; da mesma forma, junto a ela gravitaram outros organismos envolvidos nos serviços da imigração, colonização e terras. Esta inserção produziu uma ampla documentação e alguns fundos merecem destaque: o da Inspetoria de Imigração do Porto de Santos, com os documentos produzidos pelas Companhias Armadoras, como as Listas de Bordo de navios que aportaram em Santos; também os livros de registro de imigrantes e migrantes alojados na Hospedaria e, particularmente, as cartas e correspondências trocadas entre os imigrantes e seus países. Esta documentação encontra-se sob a guarda do Arquivo Público do Estado de São Paulo. 
pelo desenvolvimento dos transportes a vapor (trens e navios), os deslocamentos se tornaram "fenômenos" de massa, o que se denomina de a grande e-imigração. Esta experiência histórica ampliou as distâncias entre pessoas, dilatando a sensação de ausência, suscitando sentimentos de saudades que geraram a necessidade de comunicação e esforços de aproximação. Como bálsamo à separação, a escrita de cartas foi difundida, incorporando os populares num desafio para uma massa pouco letrada que, com grande esforço, procurava manter os vínculos. Assim, disseminaram-se novas experiências da prática epistolar, democratizando a escritura.

Dessa forma, as cartas podem ser consideradas como paradigmas dos deslocamentos,

[...] fruto do distanciamento e da separação, produto da necessidade de comunicação a distância, resultado da tentativa de anular as distâncias e, ao mesmo tempo, testemunho e prova da dilaceração em curso, além de veículo das transformações futuras. ${ }^{22}$

Os vapores cruzavam os mares transportando pessoas, mercadorias, ideias e também carregavam a mala postal, repleta de mensagens. As missivas traziam boas e más novas, comunicavam alegremente nascimentos e casamentos e, além disso, doenças e mortes; enviavam declarações de amor e fidelidade, fotos de família, encaminhavam conselhos de velhos, pedidos de ajuda e de dinheiro, expediam cartas bancárias e de chamada. Pelos correios, múltiplas histórias escritas atravessavam o oceano buscando por notícias de filhos e pais, irmãos, maridos e esposas, noivos e noivas, estas correspondências encontrando-se plenamente marcadas por múltiplos sentimentos: saudades, esperanças, amor, ódio, rancor, sonhos e medos, ilusões e desilusões.

Constituindo um movimento entre a ausência e a busca da presença, quem escrevia buscava manter contatos, laços afetivos, esperava por notícias e/ou comunicava novidades. Escrever cartas atenuava a solidão e as saudades. Entretanto, exigia tempo, dedicação e reflexão; porém, grande parte dos populares estava pouco familiarizada com o texto, que para eles era um desafio, sendo o ato de escrever um verdadeiro fardo. Para enfrentar

22 CROCI, Federico. O chamado das cartas: migrações, cultura e identidade nas cartas de chamada dos italianos no Brasil. Revista Locus, v. 14, n. 2, jul./dez. 2008, p. 30. 
estes obstáculos, criavam-se estratégias: quando não se sabia escrever ou se escrevia mal, apelava-se para que outra pessoa o fizesse.

As práticas de trocar cartas difundiram novos indicadores de comunicação e expressão, permitindo rediscutir as fronteiras entre a oralidade e o registro escrito. Apesar de os populares não dominarem estes códigos, passaram a exercitar certo "direito à escrita" 23 , mesmo que fosse se utilizando de um escrevente.

$\mathrm{Na}$ maioria das vezes, o papel de escreventes/leitores foi assumido pelo mestre-escola, pároco ou um letrado da aldeia, que podia fazer a leitura/escritura "a rogo", em troca de um agrado ou por pagamento. Eles foram protagonistas estratégicos para preencher as necessidades tanto da correspondência burocrática como das cartas particulares. Em várias missivas justifica-se a demora em mandar notícias pela dificuldade em encontrar alguém que se dispusesse a escrever, merecendo menção os esforços das mulheres, frente ao maior grau de analfabetismo feminino. Desta forma, foi criada toda uma comunidade de escreventes/leitores, destacando-se que muitas vezes essa leitura era compartilhada com outras pessoas, realizada em voz alta e em público.

A composição das cartas segue um protocolo estabelecido e difundido pelos manuais epistolares, que disseminavam os dispositivos que regulavam as práticas que passaram a ser reconhecidas e aprendidas. Instituiu-se uma estrutura, certa fórmula de uso continuado, caracterizada por elementos como: datação, tratamento, saudações, cumprimentos e abertura, desejos de saúde, despedidas, finalização, assinatura, envelope e identificação do destinatário. No caso das missivas analisadas, as fortes marcas de religiosidade, com bênçãos, graças e referências de proteção (graças a Deus, com as bênçãos de Deus, que Deus abençoe).

$\mathrm{Na}$ análise das correspondências, não se pode separar o conteúdo da forma da escritura. Cabe observar que as missivas pesquisadas apresentam um português fonético, marcado pela oralidade, uso aleatório das maiúsculas e minúsculas, problemas ou falta de pontuação, separação e/ou articulação indevida de palavras, troca de consoantes ( $\mathrm{v}$ pelo b), expressões em desuso, o que dificulta a leitura e demonstra as dificuldades destes sujeitos históricos em manter a prática da escritura. 
Quanto à caligrafia, em algumas cartas se observa a letra bem desenhada e clara, sendo muito poucas as datilografadas; em outras, devido ao baixo letramento, a letra é rústica e muito difícil de ser compreendida.

Cabe também atentar para o tipo de papel utilizado. A escolha do papel foi mais ocasional do que proposital e quando havia falta escrevia-se nas margens e bordas da folha. Aparecem nas correspondências diversos tipos de papel, como os de borda preta das missivas de luto. O uso de papel timbrado (em geral no ângulo superior esquerdo) era considerado prestigioso, podendo demonstrar vínculo profissional, prosperidade nos negócios. Em alguns poucos casos, encontram-se timbres de hotéis ou companhias de navegação, que também demonstrava status - o de viajante. ${ }^{24}$

IMAGEM 1 - CARTA DE LUTO.

ACERVO DO MEMORIAL DOS IMIGRANTES DE SÃO PAULO - APESP.

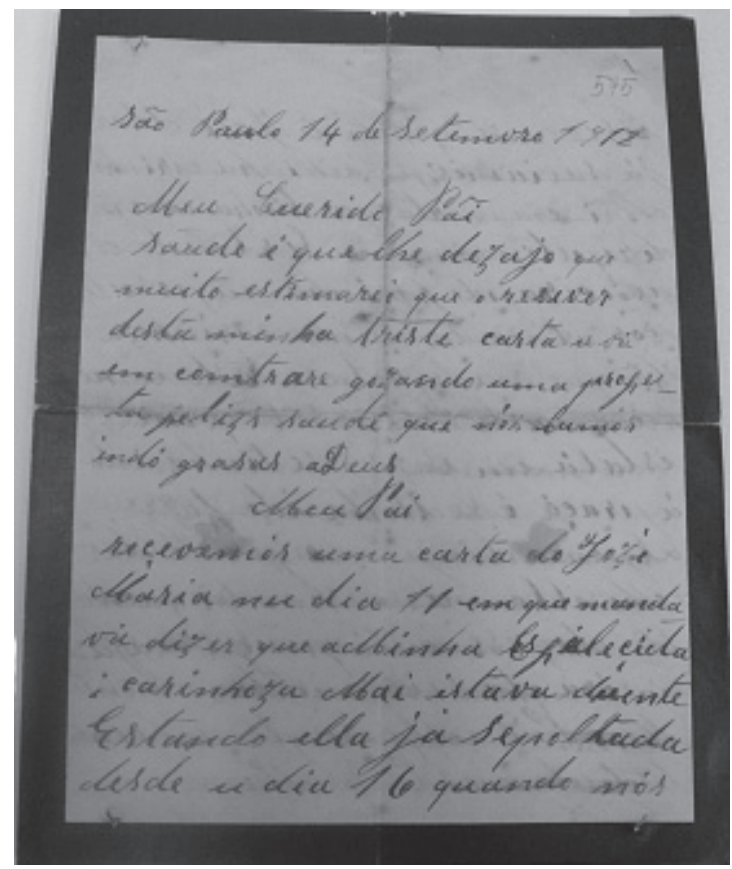

24 A difusão da indústria de papel possibilitou maior acessibilidade ao produto e a oferta de toda uma diversidade de papel no mercado (diferentes tipos, tamanhos e cores). 
IMAGEM 2.

ACERVO DO MEMORIAL DOS IMIGRANTES DE SÃO PAULO - APESP.

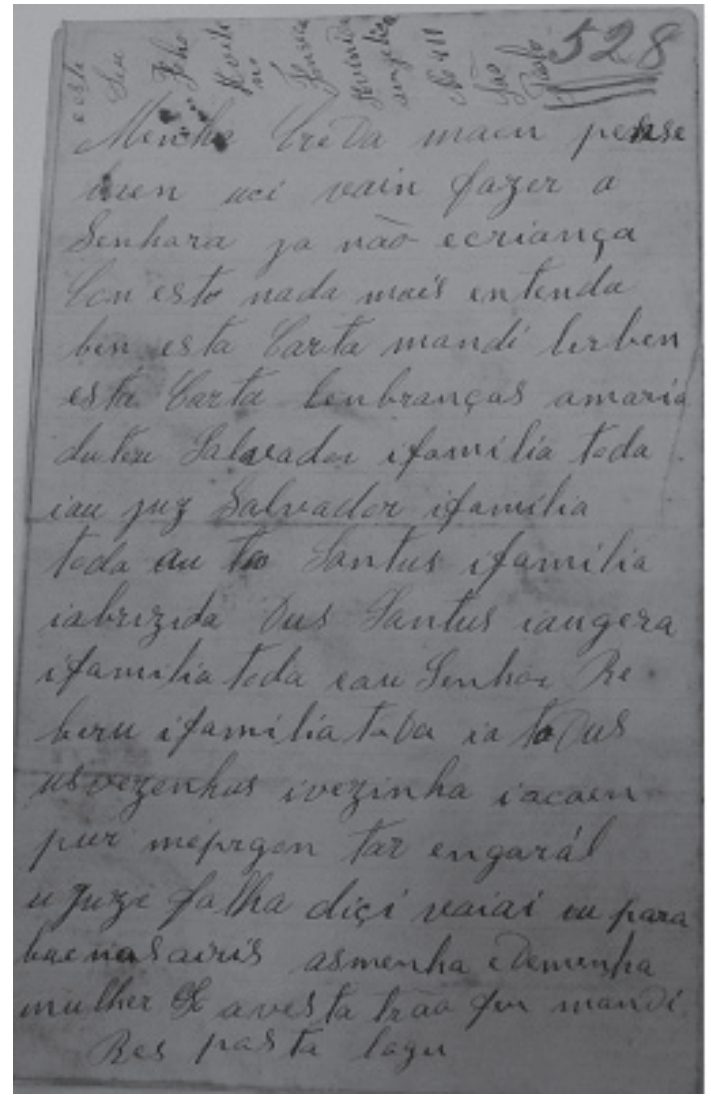

Chamadas: exigências e desejos

As cartas de chamada constituem-se numa documentação especial e reveladora. Elas foram originadas pelas exigências da burocracia no controle das saídas ou entradas, constituíram-se em fragmentos isolados, 
IMAGEM 3.

ACERVO DO MEMORIAL DOS IMIGRANTES DE SÃO PAULO - APESP.

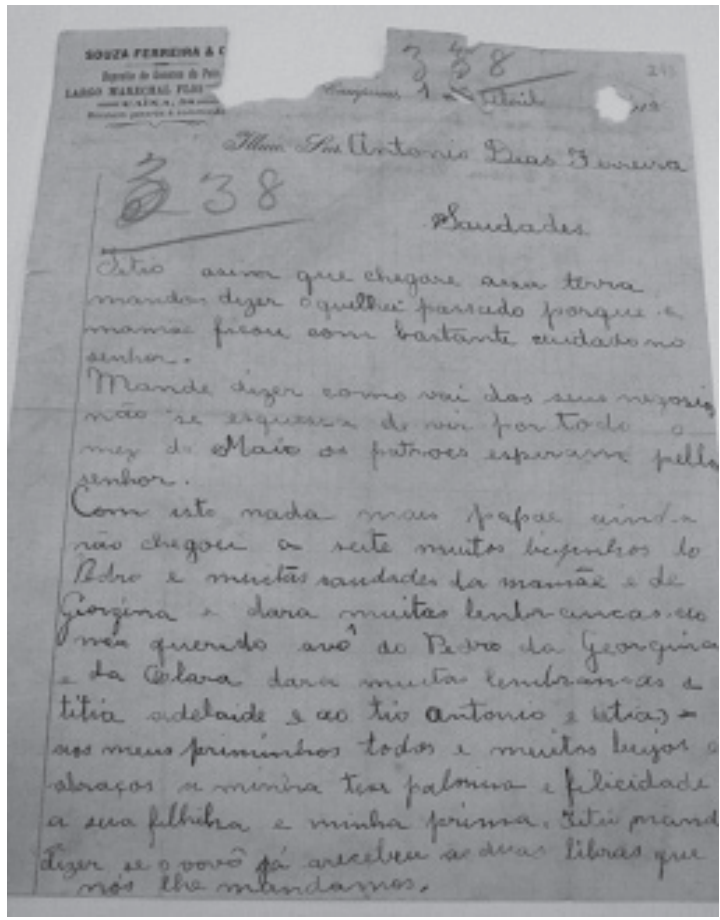

fortuitos, que compunham o pedido de passaporte em Portugal e respondiam às exigências do governo brasileiro.

Em Portugal, os processos de pedidos de passaportes eram constituídos pelo termo de abonação de identidade, requerimento e outros documentos do peticionário, ou, quando se tratava de passaporte coletivo/familiar, de todos os seus membros; excepcionalmente, integravam os bilhetes de viagem. Frequentemente incluíam-se missivas, que eram endereçadas por familiares com os quais pretendiam se juntar. $\mathrm{O}$ candidato(a) a emigrante aguardava pela carta para encaminhar os trâmites na burocracia lusitana e, quando de posse desta, deveria registrá-la em cartório, reconhecendo a sua legitimidade pela presença e assinatura de duas testemunhas. 
De acordo com a legislação portuguesa, as mulheres casadas e os filhos menores não podiam emigrar sem a autorização dos maridos e pais. Restringiam-se as saídas para o estrangeiro, já que a permanência dos laços conjugais e manutenção da família em Portugal funcionavam como um suporte, ampliando as possibilidades do retorno, e facilitavam os fluxos das remessas, que se tornaram essenciais para a família e a economia do país. A partir do Decreto n. $^{\circ} 7.427$, de 30/3/1921, mudando as práticas por novas formalidades, a carta familiar foi substituída por um tipo de impresso consular, transformando a estrutura do documento, que se tornou objetivo, não mais trazendo as referências e informações anteriores.

No Brasil, o recém-chegado ansioso entregava as "chamadas" nas mãos dos funcionários da Inspetoria de Imigração no porto de desembarque. Estas cartas podiam ser oficiais, se utilizavam de formulário próprio, como os da Inspetoria de Imigração do Porto de Santos, os concedidos por autoridade consular ou os registrados no DEOPS (Departamento Estadual de Ordem Política e Social), ou eram cartas privadas manuscritas, testemunhos da existência de um contato no Brasil, como se fossem uma chamada informal.

Apesar da anterioridade da prática das "chamadas", a partir de 1911 a legislação brasileira introduziu a obrigatoriedade deste documento para maiores de 60 anos e não aptos para o trabalho. ${ }^{25} \mathrm{O}$ elemento comprobatório que o imigrante deveria apresentar era a correspondência de chamada. $\mathrm{O}$ mesmo decreto, no seu cap. II, art. 5, especificava que o governo forneceria gratuitamente passagem, transporte, acomodações e isenções de taxas aos agricultores que, aptos para o trabalho, viessem em família, dando-se preferências para os imigrantes espontâneos chamados por parentes já estabelecidos no Brasil. Assim, conhecedores dos benefícios, vários imigrantes buscavam conseguir o documento.

Pode ser concedida passagem a Piedade de Jesus Duarte, 17 annos cega, vae para a companhia de sua mãe, em S. Paulo, a qual se chama Maria de Jesus Duarte, viúva. $3^{\mathrm{a}}$ classe. $^{26}$

25 BASSANEZI, M. Silvia et al. Repertório de legislação brasileira e paulista referente à imigração. São Paulo: EDUNESP, 2008, p. 59. Decreto 9.081, de 3 de novembro de 1911.

26 Carta do acervo do Memorial dos Imigrantes de São Paulo, hoje localizado no APESP. 
IMAGEM 4.

ACERVO DO MEMORIAL DOS IMIGRANTES DE SÃO PAULO - APESP.

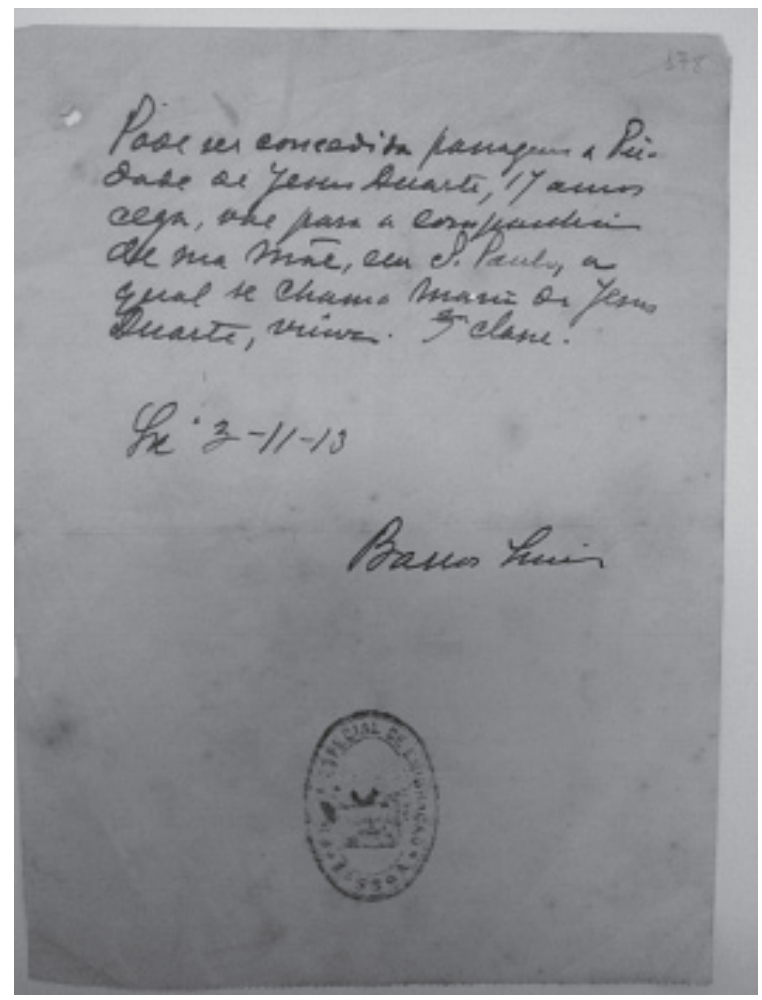

Uma pequena parte destas correspondências foi localizada nos acervos da Hospedaria dos Imigrantes, já que os recém-chegados entregavam esses documentos no porto de Santos, junto à Inspetoria de Imigração, e estes eram anexados às listas de desembarque que foram arquivadas na Hospedaria.

Este acervo está composto por aproximadamente oito mil cartas, na sua maioria de italianos. ${ }^{27}$ Neste todo, foram identificadas 154 cartas de 
portugueses; destas, cerca de 90 podem ser consideradas cartas ou declarações de chamada e outras 8 são de luto.

Os remetentes identificados são variados, em geral parentes, e entre eles encontram-se maridos e esposas, primos(as), amigos(as), afilhados(as), com destaque para filhos(as), genros e noras, sobrinhos(as), netos(as) que, acompanhando as exigências da legislação, chamavam parentes com idade avançada e/ou não aptos para o trabalho. Veja a carta datada de 1914, de João Maria Campamedo, chamando o pai:

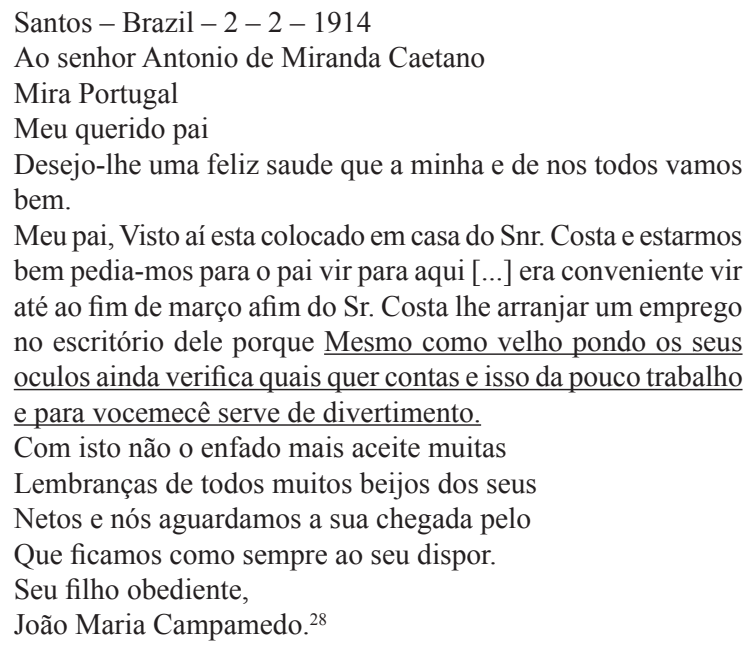

$\mathrm{Na}$ sua maior parte, as missivas visavam consentir o embarque; entretanto, em certos casos, os remetentes desestimularam a partida para o Brasil, relatando as dificuldades do cotidiano. Algumas vezes os genros se manifestavam explicitamente contra a vinda das sogras, em outras usavam de subterfúgios para dissuadi-la da viagem, denotando ressentimentos e impondo condições: caso a sogra viesse, no Brasil a situação seria diferente e ela deveria se submeter ao genro. 


\section{Escritos: desejos de diálogo}

A distância gerava saudades. Na busca de se manter os vínculos, esperava-se ansiosamente pelas cartas, evidenciando o desejo do diálogo. Queixava-se da falta de respostas. Através das missivas comunicavam-se notícias, formulavam-se perguntas, transmitiam-se orientações e manifestavam-se preocupações, explicitavam-se as estratégias pessoais e familiares. Alguns casais e parentes mantinham uma correspondência regular, em outros casos não se dava mais notícias, gerando aflição e cobrança.

Apesar de todos os esforços de aproximação, gradativamente, se estabeleciam distâncias culturais. Experiências transformadoras, como cruzar o oceano, chegada, desafios e privações no país de acolhimento produziam mudanças significativas nos sujeitos históricos e em suas trajetórias.

As cartas pesquisadas permitem notar várias questões quanto aos conteúdos, como: dificuldades, conflitos, desafios, perspectivas e possibilidades na sociedade de acolhimento; novas experiências, mudanças e permanências; escolhas, sonhos, esperanças e desalentos, desagregação e distanciamento, uma trama de questões, tensões, conflitos familiares e/ou conjugais, tendo como principal mote o reagrupamento familiar.

Como já pontuado, nos deslocamentos portugueses para o Brasil a imigração masculina foi majoritária, assim, o grosso das cartas de chamada localizadas nos processos de passaporte portugueses eram de homens chamando esposa e filhos. Alguns o faziam afetivamente, demonstrando sentimentos de saudades e tristeza, além das expressões de amor e carinho:

[...] eu para mim tenho uma fé em deus que breve mente nos vamos abraçar um outro que só açim suçegarei u meu ispirito assim que apanhar meu amor au meu lado que tam pouca alegria tenho tido em me ver tam longe de quem eu mais istimo nesta vida que tenho passado um progatorio neste mundo com a tua ausemçia não im manginas como eu ando sempre com os meus holhos rasados dagua por causa du meu amor du coração [...] arecebe mil abraços i mil beijos deste teu esposo moito umilde adeus ate deus nos deichar abraçar. ${ }^{29}$

29 Citada por SARMENTO, Carmem de Morais. "Minha querida marida", subsídios para o estudo da família emigrante através das cartas de chamada 1890-1914. Actas do Congresso Maia, História Regional e Local. 1999, p. 291. 
Outros maridos declaravam que as mulheres faziam falta no cotidiano, já que os afazeres domésticos causavam gastos (gastava tudo o que ganhava com comida e lavadeira e que muito precisava dela para isso), que se somavam às despesas com as remessas.

As mulheres que ficavam enfrentavam um cotidiano árduo, envoltas em muito trabalho, trato da lavoura e dos animais, responsabilidades dos negócios, somados aos cuidados com a casa e os filhos. Os conflitos familiares se ampliavam com a distância, perceptíveis através das queixas das esposas que se sentiam desprezadas, desamparadas, sós com os filhos, muitas vezes passando necessidades. Na correspondência, acusavam os maridos de se mostrarem indiferentes aos problemas e se manifestavam enciumadas frente a boatos e maledicências.

Já outras esposas não desejavam se unir aos maridos. A partida do marido, apesar dos múltiplos afazeres, representava certo alívio,

[...] mais senhoras de si, livres da gravidez não desejada. Muitas delas retornam à casa dos pais [...] a economia camponesa do Minho girava em torno da mulher. O governo da casa pertencia-lhes [...] estava habituada a lidar com dinheiros e pequenos negócios [...] com a emigração masculina, e na ausência prolongada dos maridos, o seu papel de gestora dos assuntos familiares mais se evidencia. ${ }^{30}$

Havia mulheres que manifestavam receios da viagem, da volta à subserviência doméstica e das múltiplas incertezas de um país desconhecido. Elas criavam desculpas para não ir (doença dela, dos filhos ou pais), buscavam escapatórias para retardar a viagem. Algumas gastavam o dinheiro enviado e não partiam; outras, depois de muitas ameaças e reclamos dos maridos, embarcavam frente ao receio de serem abandonadas.

Determinados maridos esperavam pacientemente, outros apresentavam ultimatos. Diziam que não iriam escrever mais, que aquela seria a última tentativa e intimidavam com o abandono caso elas não fossem. Manuel de Sousa Monteiro, usando de subterfúgios, relatava: 
[...] É por que tinha uma mulatinha comigo muito bonita até tu mesmo se a vises ficabas em cantada com ella e não queria que tu chigases de supetão e brigases comigo [...] e mais visto que estaba a ber no que dava o negocio a sim como já acabei e fui obrigado a hir para campos para não estar sempre mudando de escrever ora já sabes a rezão que querias saber. Já que bens não demores porque não poso com tanta despeza [...]

Circulavam em Portugal representações do Brasil como um país de mulheres belas e insinuantes, o que difundia insegurança e ciúmes e ampliava a sensação de abandono.

Outras esposas ansiavam pelo reencontro, insistiam, pressionavam pela chamada, ameaçavam partir para o Brasil, mesmo sem autorização; buscavam brechas e alternativas. Os maridos respondiam com mensagens apaziguadoras, outros impunham condições (não trazer a mãe, não vir com os irmãos, conter o mau gênio) e diversos acabavam cedendo às solicitações e mandavam-nas chamar. Sós, elas enfrentavam a saga do deslocamento transatlântico, a chegada num país desconhecido, embarcavam carregando os filhos menores, em busca do sonho de voltar a reconstituir a família.

Havia casos nos quais os maridos não manifestavam qualquer desejo do reencontro. Eles viajaram sós ou com amigos, reuniram-se com os conterrâneos estabelecidos, encontraram atividades, usufruíam de liberdade (impossível na sociedade de onde vinham), não desejavam voltar à situação anterior, referiam-se de modo indefinido à reunificação familiar. Nas missivas, eram poucas as referências ao regresso; alguns homens não chamaram as esposas, nunca retornaram, deixavam de mandar notícias, constituindo novas famílias no Brasil. As mulheres se deixaram ficar envoltas em saudades e numa espera sem fim; tornavam-se "viúvas de maridos vivos".

\section{Escritos: redes}

Apesar das distâncias, na correspondência se observa como os maridos se preocupavam e buscavam influir nas questões no cotidiano das aldeias, nos negócios, problemas com as terras e com a criação; assumiam 
um discurso de recomendação de como tratar, o que, para quem, quando e por quanto vender.

Também se percebem as afetividades e rivalidades entre parentes, conterrâneos e vizinhos, mas principalmente as amizades, com destaque para os laços de compadrio. Com a madrinha se deixavam as crianças, quando não se podia trazê-las; se contava com o compadre para a intermediação nos negócios e na viagem. Alguns maridos, ou por cuidados ou demonstrando pouca confiança nas mulheres em relação ao trato com o dinheiro, preferiam enviar as remessas para intermediários (compadres), para quem delegavam o encaminhamento dos negócios, pagamento de contas e outras ações; também a compra dos bilhetes, providências burocráticas da documentação (passaporte) e do embarque da família.

Quanto à viagem, os homens, que já haviam passado pela experiência anteriormente, norteavam suas esposas e familiares em todos os detalhes: o que trazer ou vender e a que preço, como compor a mala (roupas, enxoval, utensílios), marcas de identificação (faça três cruzes negras no baú), atenções com as crianças, comidas para levar, orientações de embarque, como seria a travessia, muitas recomendações quanto ao comportamento (cuidados e postura de recato), além das indicações de como ocorreria o desembarque.

Lidas e relidas em público, as cartas funcionam como elementos de divulgação e propaganda das representações do Brasil como um país de possibilidades, alimentando sonhos e estimulando as partidas.

Estas missivas se apresentam como uma documentação com grande potencial, por registrarem diferentes experiências de deslocamentos. Revelam relações pessoais, familiares (desagregação, distanciamento e reencontro familiar), laços de parentesco, compadrio e conterraneidade; envolvem solidariedade nas dificuldades, suportes afetivos, expondo interesses, perspectivas e possibilidades. Desvelam cobranças, compromissos, desabafos, conflitos, rompimento de vínculos, inveja, intriga e ciúmes, assim como outros sentimentos, sensibilidades, sonhos, confidências, intimidades, segredos, ideias, projetos e opiniões.

Cabe ressalvar entre os vários mecanismos e estratégias que viabilizaram os deslocamentos a constituição de redes, tanto as institucionais (subsidiadas ou não), envolvendo agenciadores, aliciadores, sistema de propaganda e meios de comunicação (feitos pelas próprias instituições do governo no exterior ou por particulares), agências e companhias de nave- 
gação, como as cadeias informais com a difusão de informação, chamadas, acolhimento, estabelecimento de relações interpessoais. As cartas constituem um registro e mote dessas redes, que funcionaram como veículos de difusão da imigração, favorecendo as saídas, constituindo circuitos que envolviam parentes, amigos, conterrâneos, através de chamadas e convites a parentes e conterrâneos, estabelecendo bases de apoio que ajudavam a integração, a enfrentar as dificuldades na sociedade de acolhimento, ampliando as possibilidades de achar colocação, montar negócios e de enfrentar as agruras do cotidiano.

Para o pesquisador, as correspondências provocam muitas inquietações sobre os desdobramentos destas trajetórias: se a reunificação familiar foi possível, se maridos e esposas se reencontraram, ou se o Manuel acertou-se com a bela mulata brasileira ou voltou para sua esposa portuguesa, se as sogras e genros se aquietaram na sociedade de acolhimento... Mas, infelizmente, é impossível responder a todas estas inquietações. Se a missão do historiador é questionar o passado contando suas histórias, cabe encerrar esta narrativa com uma adaptação do dito popular: "Entre uma carta e outra, quem quiser que conte outra..."

\section{Referências}

CORTI, Paola. Storia delle migrazioni internazionali. Roma: Editori Laterza, 2007. CROCI, Federico. O chamado das cartas: migrações, cultura e identidade nas cartas de chamada dos italianos no Brasil. Revista Locus, v. 14, n. 2, jul./dez. 2008.

GOMES, Ângela de Castro. Escrita de si, escrita da história. Rio de Janeiro: FGV, 2004.

LEITE, Joaquim da Costa. O Brasil e a emigração portuguesa (1855-1914). In: FAUSTO, Boris (Org.). Fazer a América. São Paulo: EDUSP, 2000.

LOBO, Eulália Maria L. Imigração portuguesa no Brasil. São Paulo: Hucitec, 2001. MATOS, M. Izilda S. de. Cotidiano e cultura. Bauru: EDUSC, 2002. . Deslocamentos \& histórias: os portugueses. Bauru/Porto: EDUSC/ CEPESE, 2008. 
MOURA, Soraya; PAIVA, Odair da Cruz. Hospedaria de Imigrantes de São Paulo. São Paulo: Paz e Terra, 2008.

PEREIRA, Miriam Halpern. A politica portuguesa de emigração, 1850-1930. Bauru: EDUSC, 2002.

SARMENTO, Carmem de Morais. "Minha querida marida": subsídios para o estudo da família emigrante através das cartas de chamada 1890-1914. Actas do Congresso Maia, história regional e local. Maia, 1999.

SILVA, Brasilina da Assunção Oliveira Almeida Pereira da. Cartas de chamada a dimensão familiar da emigração Sernancelhe no início do séc. XX. Tese (Mestrado em História) - Universidade Portucalense. Porto, 2006.

Recebido em janeiro de 2012. Aprovado em fevereiro de 2012. 